\title{
Mutual Coupling Reduction between Asymmetric Reflectarray Resonant Elements
}

\author{
M. Hashim Dahri ${ }^{1}$, M. H. Jamaluddin ${ }^{2}$, M. Inam ${ }^{3}$, M. R. Kamarudin ${ }^{4}$ \\ ${ }^{1,2,3}$ Wireless Communication Centre, Faculty of Electrical Engineering, Universiti Teknologi Malaysia, \\ Johor Bahru 81310, Malaysia \\ ${ }^{4}$ Centre for Electronic Warfare Information and Cyber, Cranfield Defence and Security, Cranfield University, \\ Defence Academy of the United Kingdom, Shrivenham SN6 8LA, U.K
}

\begin{tabular}{l}
\hline \hline Article Info \\
\hline Article history: \\
Received Dec 11, 2017 \\
Revised Mar 7, 2018 \\
Accepted Mar 14, 2018 \\
\hline
\end{tabular}

Keyword:

Electric field

Mutual coupling

Reflection loss

Reflection phase

Unit cell

\section{Corresponding Author:}

Mohd Haizal Jamaluddin,

Wireless Communication Centre,

Faculty of Electrical Engineering,

Universiti Teknologi Malaysia,

Johor Bahru 81310, Malaysia.

Email: haizal@fke.utm.my

\begin{abstract}
A physically asymmetric reflectarray element has been proposed for wide band operations. The dual resonant response has been introduced by tilting one side of the square path element. The numerical results have been analyzed in the frequency band between $24 \mathrm{GHz}$ to $28 \mathrm{GHz}$ where a reflection phase range of more than $600^{\circ}$ has been achieved. The proposed asymmetric element can produce mutual coupling with adjacent elements on a reflectarray. This effect has been monitored by placing the elements in a mirror configuration on the surface of reflectarray. The single unit cell element results have been compared with conventional 4 element unit cell and proposed mirroring element configuration. The proposed mirroring element technique can be used to design a broadband reflectarray for high gain applications.
\end{abstract}

Copyright $@ 2018$ Institute of Advanced Engineering and Science. All rights reserved.

\section{INTRODUCTION}

The array of microstrip patches printed on a flat grounded dielectric substrate and fed by a horn describes the architecture of a reflectarray antenna. It can scan its beam to wide angles by maintaining low profile design. The phased arrays and parabolic reflectors are its main competitors [1]. The main drawback associated with phased arrays is their complex design which also introduces additional losses especially at higher frequencies. Parabolic reflectors are also difficult to design at millimeter waves for high gain performance. On the other hand, the design simplicity of reflectarrays makes it suitable for high frequency operations. However the narrow bandwidth with low gain performance is its main operational limitation. This issue is even more challenging at higher frequencies such as millimeter waves due to shorter operational wavelengths [2]-[4]. The performance of a reflectarray antenna can be improved by suitably designing its unit cell patch element in an infinite array approach. Its bandwidth can be improved by enhancing the unit cell reflection phase range while its gain depends on the losses contributed by its unit cell [5], [6]. The conventional patch elements such as square and circular can provide low loss performance however their bandwidth is limited due to their reflection phase range narrower than a full $360^{\circ}$ cycle [7]. Some extraordinary efforts are required to enhance the reflection phase range of a unit cell beyond a conventional $360^{\circ}$ phase swing. This can be done by introducing an extra resonance in the reflection response of the unit cell element. However, this phenomenon could also produce extra losses and mutual coupling [8], [9] 
between the adjacent elements. Mutual coupling can be reduced by increasing the distance between the elements [1]. However, it limits the gain performance and increases the profile of the reflectarray.

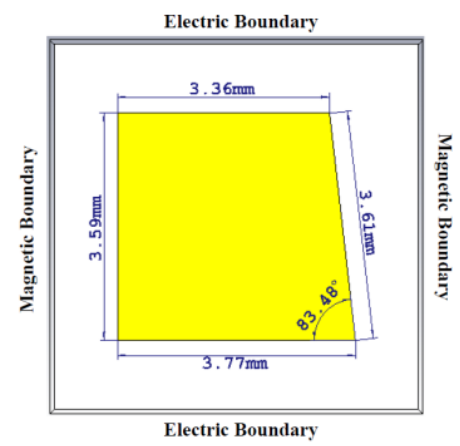

Figure 1. Asymmetric reflectarray unit cell element

Therefore in this work an asymmetric reflectarray unit cell element as shown in Figure 1, has been proposed to enhance its bandwidth performance at $26 \mathrm{GHz}$. The performance of the unit cell element has been analyzed in an infinite array approach by enclosing it within magnetic and electric boundaries. An extra resonance has been produced by tilting one side of a square patch element from $90^{\circ}$ to $83.48^{\circ}$. The full parametric studies of the unit cell has already been presented in [10]. The resonance behavior of a single patch unit cell and a 4 element unit cell has been thoroughly examined with $0.254 \mathrm{~mm}$ thick Rogers 5880 substrate. A technique has been introduced to limit the mutual coupling between the elements which is caused by the asymmetry in the physical design of the elements.

\section{RESULTS AND DISCUSSIONS}

The selected design of unit cell element has been investigated using Finite Integral Method (FIM) with infinite array approach. It has been analyzed that, by tilting one side of the square patch element offers broadband resonant features. The tilting of the one side of the element creates asymmetry between two sides and introduces two different lengths for the same element at opposite sides. These two lengths are aligned in the same direction of the incident electric field as shown in Figure 2(a), creating two different values of reflected electric field (E1 and E2). These two different magnitudes of reflected electric field are the main reason behind the dual resonance response of the element which can be seen from Figure 3(a). As the single element is analyzed with infinite array approach, this dual resonance response should be applicable for any number of elements on a reflectarray. However, when a 4 element unit cell comprising of same elements has been calculated, its reflection response deteriorated. This can clearly be observed from Figure 3(a) where its two resonances alongside its reflection loss values considerably changed from their original position.

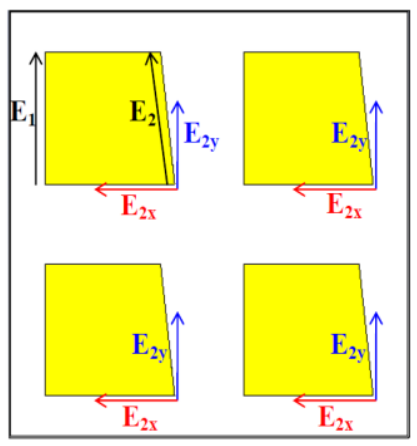

(a)

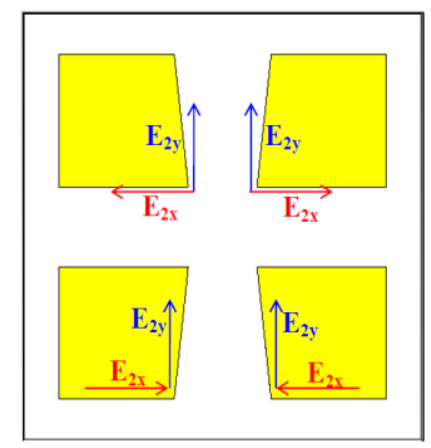

(b)

Figure 2. Arrangement of patch elements for reflectarray (a) 4 element unit cell (b) unit cell with mirroring the elements 


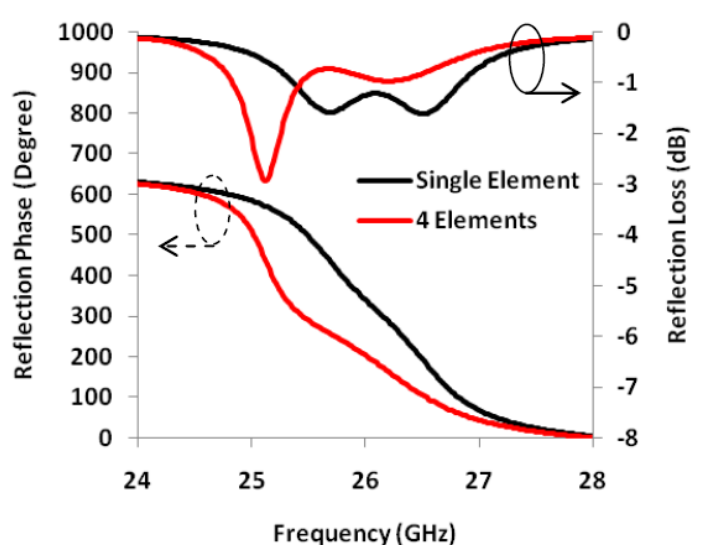

(a)

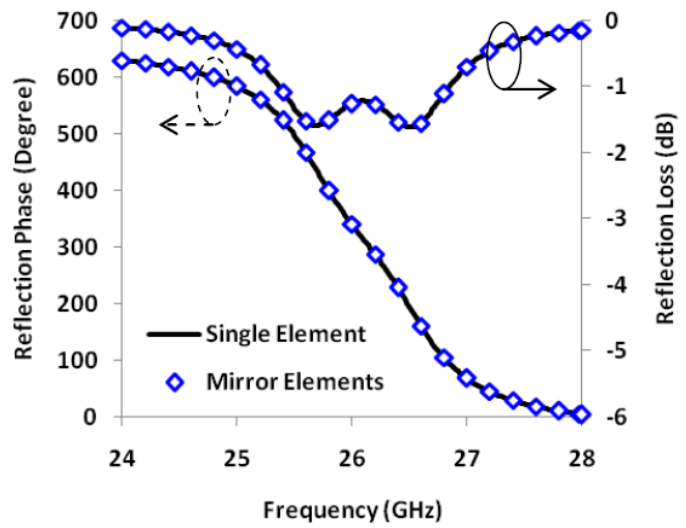

(b)

Figure 3. Reflection loss and reflection phase curves of reflectarray unit cells (a) Comparison between single and 4 element unit cells (b) Comparison between single unit cell and unit cell with mirroring the elements

The reason behind that is the tilted electric field $\left(\mathrm{E}_{2}\right)$ which generates two more electric components which are $E_{2 x}$ and $E_{2 y}$. $E_{2 y}$ is already in the same direction of $E_{1}$ whereas $E_{2 x}$ is in the orthogonal direction to it. The $\mathrm{E}_{2 \mathrm{x}}$ components of all elements in the reflectarray are added up together due to the same direction to generate mutual coupling as shown in Figure 2(a). This mutual coupling can change resonance frequency, reflection phase and can introduce high cross polarization with high side lobe levels for a reflectarray.

Table 1. The Reflection Response of Reflectarray Unit Cell Elements

\begin{tabular}{cccc}
\hline Unit Cell Type & $\begin{array}{c}\text { Maximum Reflection } \\
\text { Loss }(\mathrm{dB})\end{array}$ & $\begin{array}{c}\text { Resonant } \\
\text { Frequency }(\mathrm{GHz})\end{array}$ & $\begin{array}{c}\text { Slope of Reflection } \\
\text { Phase }(\% / \mathrm{GHz})\end{array}$ \\
\hline Single & 1.6 & 26 & 290 \\
4 Element & 2.9 & 25.7 & 505 \\
4 Element Mirror & 1.6 & 26 & 290 \\
\hline
\end{tabular}

The mutual coupling effect can also be observed from Table 1, where reflection response of each type of element is recorded. It can be seen from Table 1 that, the resonant frequency of 4 element unit cell changed from $26 \mathrm{GHz}$ to $25.7 \mathrm{GHz}$. Its maximum reflection loss value has also been increased up to $2.9 \mathrm{~dB}$ as compared to $1.6 \mathrm{~dB}$ of single unit cell. The mutual coupling also affects and increases the slope of reflection phase of 4 element unit cell by $505 \% / \mathrm{GHz}$. A smoother reflection phase curve with low slope ensures a wider bandwidth performance. This shows that, introduction of mutual coupling between the elements can increase the loss, decrease the bandwidth and can drastically affect the gain and bandwidth performance of a full reflectarray as a whole.

This issue of mutual coupling can be avoided by physically mirroring the orientation of the elements as shown in Figure 2(b). The same technique is used in [11] where the elements with stub lines are used. However in this work, this technique is applied on the physically asymmetric elements. By doing so, all $\mathrm{E}_{2 \mathrm{x}}$ components which are responsible for creating mutual coupling are canceled with each other due to opposite directions. This concept can be proved by analyzing Figure 3(b) where mirror elements are showing the same resonant response as of a single unit cell element. Table 1 also confirms the elimination of mutual coupling where reflection response of unit cell with mirror orientation coincides with the reflection response of single unit cell. The reflection loss and reflection phase curves of both unit cells are exactly same which can provide ease of creating a large reflectarray.

\section{CONCLUSION}

The bandwidth of a square patch reflectarray element can be enhanced by introducing asymmetry in its design with a tilted side. This effect can introduce two narrowly separated resonances with reflection phase ranging beyond $600^{\circ}$ mark. The asymmetrical designs of elements on a reflectarray can introduce mutual coupling effects which can completely alter the resonance behavior of the elements. This effect can 
be avoided by physically mirroring the orientation of the elements on the surface of the reflectarray. This technique cancels the orthogonality generated unwanted electric field components in reflectarray and provides ease to design a large reflectarray antenna for possible high gain operation.

\section{ACKNOWLEDGEMENTS}

This project is sponsored by the Ministry of Education Malaysia, Ministry of Science Technology and Innovation (MOSTI) and Universiti Teknologi Malaysia under Vot 4J211, Vot 03G33 and Vot 4S134.

\section{REFERENCES}

[1] J. Huang and J. Encinar, "Reflectarray antennas", USA: Wiley Inter Science, 2007.

[2] M. H. Dahri, M. H. Jamaluddin, M. Inam, and M. R. Kamarudin, "A Review of Wideband Reflectarray Antennas for 5G Communication Systems," IEEE Access, vol. 5, pp. 17803-17815, 2017.

[3] M. H. Dahri, M. R. Kamarudin, M. H. Jamaluddin, and R. R. Selvaraju, "Performance Investigation of Reflectarray Resonant Elements for 5G Communications," in IEEE Asia-Pacific Conference on Applied Electromagnetics, 2016, p. Accepted.

[4] F. Mohd, R. Sauleau, Z. Johari, M. K. A. Rahim, and A. M. Huda, "A Novel Right Handed Circular Polarization Folded Reflectarray Antenna at 60 GHz," Int. J. Electr. Comput. Eng., vol. 7, no. 3, pp. 1580-1587, 2017.

[5] M. R. Chaharmir, J. Shaker, and H. Legay, "Broadband design of a single layer large reflectarray using multi cross loop elements," IEEE Trans. Antennas Propag., vol. 57, no. 10 PART 2, pp. 3363-3366, 2009.

[6] M. Inam and M. Y. Ismail, "Reflection loss and bandwidth performance of X-band infinite reflectarrays: simulations and measurements," Microw. Opt. Technol. Lett., vol. 53, no. 1, pp. 77-80, 2011.

[7] D. M. Pozar, D. Targoski, H. D. Syrigos, S. D. Targonski, and H. D. Syrigos, "Design of millimeter wave microstrip reflectarrays," IEEE Trans. Antennas Propag., vol. 45, no. 2, pp. 287-296, 1997.

[8] M. H. Jamaluddin, R. Gillard, R. Sauleau, and M.-A. Milon, "Perturbation Technique to Analyze Mutual Coupling in Reflectarrays," IEEE Antennas Wirel. Propag. Lett., vol. 8, pp. 697-700, 2009.

[9] M. R. Islam, S. A. Waheeb, R. Sarah, M. S. Yasmin, and M. H. Habaebi, "A 2X2 MIMO Patch Antenna for MultiBand Applications," Indones. J. Electr. Eng. Informatics, vol. 5, no. 4, pp. 383-389, 2017.

[10] M. H. Dahri, M. R. Kamarudin, M. H. Jamaluddin, M. Inam, and R. Selvaraju, "Broadband Resonant Elements for 5G Reflectarray Antenna Design,” TELKOMNIKA (Telekommunication Computing, Electronics and Control), vol. 15, no. 1, 2017.

[11] R. S. Malfajani and Z. Atlasbaf, "Design and Implementation of a Dual-Band Single Layer Reflectarray in X and K Bands," IEEE Trans. Antennas Propag., vol. 62, no. 8, pp. 4425-4431, Aug. 2014.

\section{BIOGRAPHIES OF AUTHORS}

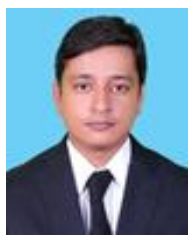

Muhammad Hashim Dahri received the Bachelor of Engineering in Telecommunications from Mehran University of Engineering and Technology (MUET) Pakistan in 2010. He did his Masters by research in Electrical Engineering from Universiti Tun Hussein Onn Malaysia (UTHM) in 2014. He is now working towards his Ph.D degree from Wireless Communication Centre (WCC) Univerisiti Teknologi Malaysia (UTM). His research interests include reflectarray antennas, planar printed antennas and tunable materials for antenna design. He has published more than 20 research papers in various indexed journals and conference proceedings.

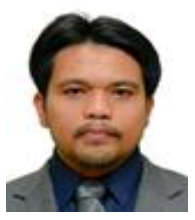

Mohd Haizal Jamaluddin received bachelor's and master's degrees in electrical engineering from Universiti Teknologi Malaysia, Malaysia, in 2003 and 2006, respectively, and the Ph.D. degree in signal processing and telecommunications from the Université de Rennes 1, France, in 2009, with a focus on microwave communication systems and specially antennas such as dielectric resonator and reflectarray and dielectric dome antennas. He is currently a Senior Lecturer with the Wireless Communication Centre, Faculty of Electrical Engineering, Universiti Teknologi Malaysia. His research interests include dielectric resonator antennas, printed microstrip antennas, MIMO antennas and DRA reflectarray antenns. He has published more than 25 papers in reputed indexed journals and conference proceedings.

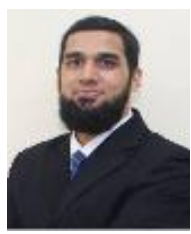

Muhammad Inam Abbasi completed his BSC in Electrical Engineering with major in Telecommunication in 2008 from Centre for Advanced Studies in Engineering (CASE Islamabad), University of Engineering and Technology (UET, Taxilla), Pakistan. He joined Wireless and Radio Science Centre (WARAS), Universiti Tun Hussein Onn Malaysia (UTHM) as a Graduate Research Assistant in 2009 where he completed his Master by Research and Ph.D. in Electrical Engineering in 2011 and 2016 respectively. Currently, He is working as a Post-Doctoral research fellow at Wireless Communication Centre (WCC), Universiti Technologi Malaysia (UTM). His recent research interest lies in high performance planar and printed antenna design, passive and reconfigurable reflectarray 
and planar reflector antennas, novel materials for the design of enhanced performance antennas. Dr. Inam has published one book and more than 40 research papers in internationally indexed journals and conferences.

Muhammad Ramlee Kamarudin obtained his first degree from Universiti Teknologi Malaysia (UTM), Johor Bahru, Malaysia, with honors, majoring in electrical and telecommunication engineering and graduating in 2003. He received the M.S. degree in communication engineering in 2004 from the University of Birmingham, Birmingham, UK, and later he obtained his Ph.D. degree in 2007 from the same University under the supervision of Professor Peter Hall. Dr Kamarudin is currently working as a Senior Lecturer at Centre for Electronic Warfare, Information and Cyber (EWIC), Cranfield Defence and Security, Cranfield University, UK. He is an author of a book chapter of a book entitled Antennas and Propagation for Body- Centric Wireless Communications and has published more than 200 technical papers in journals and proceedings including IEEE Transaction on Antenna and Propagation (TAP), IEEE Antennas and Wireless Propagation Letter (AWPL), IEEE Antenna Magazine, IEEE Access, International Journal of Antennas and Propagation (IJAP), Progress in Electromagnetics Research (PIER), Microwave and Optical Technology Letters (MOTL), and Electronics Letters. His research interests include antenna design for 5G, wireless on- body communications, in- body communications (implantable antenna), RF and microwave communication systems, and antenna diversity. Moreover, Dr Kamarudin is an IEEE Senior Member (SMIEEE), a Member of IET (MIET), an Executive Member of Antenna and Propagation (AP/MTT/EMC), Malaysia Chapter, and a Member of IEEE Antennas and Propagation Society, IEEE Communication Society, IEEE Microwave Theory and Techniques Society and IEEE Electromagnetic Compatibility Society. 